\title{
Perspectivas do controle da infecção hospitalar e as novas forças sociais em defesa da saúde
}

\author{
Prospects for controlling hospital infection \\ and the new social forces for upholding healthcare
}

${ }^{1}$ Departamento Regional de Saúde I, Secretaria de Estado da Saúde. Av. Conelheiro Crispiniano 20, República. 01037-000 São Paulo SP. paulopuccini@gmail.com

\begin{abstract}
This paper discusses hospital infections based on the methodological concept of concrete totality and the resulting explanatory model of social determination, as critical paths for putting such occurrences and the social intervention possibilities to control them into context. It assesses the prospects for control by considering the advances in knowledge and control programs and the post-constitutional Brazilian institutional setting. It concludes that the increasing intervention by the judiciary and the Public Prosecutor's office, regarding issues involving hospital infection and the existing difficulties for control, reflect the level of healthcare service qualification in Brazil. It suggests that such judicial intervention contributes to the democratization process of healthcare policies and adds to the efforts of society in general to uphold the right to healthcare. It considers that following up the conditions under which control takes place in each institution may reveal important information that can be taken as markers for the general quality of the services and care provided, thereby becoming an instrument for a broad joint effort by the Public Prosecutor's office and healthcare institutions along with citizen participation.
\end{abstract}

Key words Right to healthcare, Health law, Public Prosecutor, Citizen participation, Hospital infection
Resumo $O$ artigo discute as infecções hospitalares com base no conceito metodológico da totalidade concreta e no consequente modelo explicativo da determinação social, como caminhos críticos para contextualizar essas ocorrências e as possibilidades de intervenção social para o seu controle. Discute as perspectivas de controle considerando o avanço dos conhecimentos e dos programas de controle, e o quadro institucional brasileiro pós-constituinte. Conclui que a crescente intervenção da justiça e do Ministério Público em questões envolvendo a infecção hospitalar e as dificuldades existentes de controle refletem o patamar de qualificação dos serviços de saúde no Brasil. Sugere que tal intervenção da justiça contribui para o processo da democratização da política de saúde e soma-se aos esforços da sociedade em geral na defesa do direito à saúde. Considera que o acompanhamento das condições em que se processa o controle em cada instituição pode produzir importantes informações, constituindo-se numa condição marcadora da qualidade geral dos serviços e da assistência prestada, transformando-se num instrumento para um amplo trabalho conjunto do Ministério Público com instituições da saúde e da participação cidadã.

Palavras-chave Direito à saúde, Direito sanitário, Ministério Público, Participação cidadã, Infeç̧ão hospitalar 


\section{Introdução}

A partir de hoje, 15 de maio de 1847, todo estudante ou médico, é obrigado, antes de entrar nas salas da clínica obstétrica, a lavar as mãos, com uma solução de ácido clórico, na bacia colocada na entrada. Esta disposição vigorará para todos, sem exceção ${ }^{1}$ (p. 236). Ignaz Philipp Semmelweis (1818-1865)

Quando em meados do século XIX o médico Ignaz Semmelweis, com sua origem húngara e ideias questionadoras em meio ao conservador círculo de colegas em Viena, comprovou a hipótese de que doenças graves (doenças infecciosas na época não se conhecia a existência de microorganismos) eram decorrentes de procedimentos terapêuticos, foi por muitas vezes alvo de zombarias e até perseguido ${ }^{2}$.

Polemizando com os cientistas da época que refutavam seu trabalho por não se enquadrar na doutrina vigente das alterações histológicas e levantar a hipótese da presença de eventuais partículas estranhas ("partículas cadavéricas"), Semmelweis, com seu falar irreverente e ácido de "boca de brasa", aos moldes do nosso poeta Gregório de Matos, acusava: "A sua doutrina assenta nos cadáveres das puérperas assassinadas pela ignorância [...] estou convencido de que se trata de evitar a mortandade de milhares e milhares de mães e lactentes e diante disto, algumas dezenas de professores carecem de importância..."

Nada corrobora tanto - como esse episódio da história das ciências da saúde - com as proposições que Thomas $\mathrm{Kuhn}^{3}$ ressaltou ao discutir os modos conflituosos de como se processa a substituição dos paradigmas da ciência no contexto de posturas interessadas e conservadoras da própria comunidade dos cientistas.

Porém, foi com Semmelweis que sabão, escovas e ácido clórico tiveram entrada na prática hospitalar. A despeito de opositores, ele introduziu medidas básicas de controle em sua unidade (isolamento dos casos; lavagem das mãos e fervura de instrumental) e a mortalidade das parturientes, que chegara aos $18,3 \%$, caiu para uma média de 3,0\% nos meses seguintes à adoção desses cuidados básicos ${ }^{4}$.

\section{O fenômeno-doença e as infecções hospitalares}

Com as pesquisas do cientista francês Louis Pasteur, a hipótese de Semmelweis, construída com sua perspicácia e perseverança na observa- ção empírica das ocorrências e do comportamento das pessoas, ganhou justificação teórica. Desconhecidas e microscópicas criaturas haviam sido identificadas: a chamada era bacteriológica iniciava, de forma avassaladora, o seu período de domínio explicativo da causação das doenças.

Nos anos seguintes, a observação e o estudo da determinação das doenças infecciosas expuseram a limitação da explicação unicausal e simplista do microorganismo como condição necessária e suficiente para a ocorrência da infecção e do adoecimento. Novos postulados para controlar os exageros na busca de microorganismos para cada doença foram construídos (formulados por Henle e adaptados por Robert Koch, em 1882, posteriormente revistos por Alfred Evans, em 1976). As teorias da determinação das doenças ampliam-se e, após abandonar os templos religiosos, abandonam o deus-microscópio e caminham na direção de um modelo explicativo histórico e integrante da totalidade social. Essa articulação do fenômeno-doença com a vida social e coletiva abre novas possibilidades para a atuação dos profissionais de saúde, colocando tal fenômeno ao alcance, também, da atuação da sociedade como um todo, que é convocada a cuidar da saúde coletiva e das condições para a produção e reprodução de uma vida saudável.

Entretanto, ainda hoje permanece um rescaldo de concepção, uma tentação, verificada mesmo entre estudantes universitários, em considerar que o entendimento da causação da doença, segundo o processo no qual combinam-se múltiplos fatores socialmente estruturados seria um caminho explicativo para as doenças não-infecciosas (diabetes, hipertensão, coronariopatias), porém desnecessário no caso das doenças infecciosas $^{5}$. Nestas, seria fútil considerar outras questões diante da objetiva e positiva presença do germe a ser isolado, identificado e combatido com os mais sofisticados produtos antimicrobianos e outros procedimentos germicidas. É essa tentação, compartilhada por muitos, que justifica uma presunção de que seria possível erradicar as doenças infecciosas, quer nos atuais serviços de saúde quer na sociedade em geral, e que isso não ocorreu, apenas, por uma passageira falta de empenho e de excelência da tecnologia de combate.

Assim, a perda da consideração da vida social e coletiva como essência da produção da doença, na qual a dinâmica de uma estrutura-contexto produz o fenômeno, leva por conseguinte à perda do entendimento do próprio fenômeno. Kosik $^{6}$ enfatiza que sem a compreensão da realidade como totalidade concreta - que se trans- 
forma em estrutura significativa para cada fato ou conjunto de fatos -, o conhecimento da realidade concreta não passa de mística, ou coisa incognoscível em si. A concreticidade não nega o conhecimento da existência ou da objetividade dos fenômenos, mas reconhece que é necessário articulá-los com uma totalidade concreta, para compreendê-los a partir de suas mútuas determinações. A pseudoconcreticidade é justamente a pretensa existência autônoma dos produtos do homem e a redução do homem ao nível da práxis utilitária. A realidade social não é considerada totalidade concreta se o homem, no âmbito da totalidade, é considerado apenas objeto, e se na práxis histórico-objetiva da humanidade não se reconhece a importância primordial do homem como sujeito.

Com a intenção de uma abordagem crítica sobre o fenômeno das infecções hospitalares, adota-se o caminho metodológico proposto, reafirmando-se o entendimento de que a doença é uma vivência pessoal, necessita de um cuidado individual, mas é social a questão das suas causas e as possibilidades de cada indivíduo recuperar-se.

\section{O controle das infecções hospitalares e a hipossuficência da sociedade}

A lavagem das mãos ainda hoje é uma ação das mais importantes para o controle das infecções relacionadas à assistência à saúde - IrAS (denominação que engloba a infecção hospitalar). A aplicação daqueles princípios básicos estabelecidos por Semmelweis e de outras medidas envolve, atualmente, uma equipe composta por médicos, enfermeiros, farmacêuticos, microbiologistas, administradores, todos responsáveis pela execução das ações. Organizados formalmente e compondo uma comissão de controle no interior das instituições de saúde, essa equipe tem a função de detectar casos de infecção; elaborar normas de padronização dos procedimentos; promover treinamento dos profissionais sobre a prevenção e o controle das infecções; controlar a prescrição de antibióticos; recomendar medidas de precaução e isolamento; participar na padronização para a aquisição de materiais e equipamentos.

Essas são funções que fundamentam as exigências básicas fixadas na legislação atual: estabelecer um grupo responsável pela execução e acompanhamento de medidas de controle (a comissão de controle - CCIH), elaborar um plano formal de ação, avaliando e divulgando resultados (o plano de controle $-\mathrm{PCIH})^{7,8}$.
Há muitos esforços das autoridades públicas visando a regulamentação das atividades de controle, a disseminação de informações por meio de cursos e manuais, como também esforços de associações de profissionais de saúde e outras entidades privadas que tem contribuído na formação, atualização e motivação do pessoal da área.

Entretanto, é forçoso reconhecer que, embora necessário e valoroso esse esforço, seria tolo considerar que a atividade de controle de infecção, produto do conjunto de aspectos técnicogerenciais e políticos envolvidos, poderia ser facilmente solucionável como uma ilha de excelência técnica em meio às condições contextuais e apesar da natureza total e interdependente do funcionamento de uma unidade hospitalar.

Diversos estudos sobre as condições do controle da infecção hospitalar revelam a fragilidade da organização dessa atividade nas instituições, apesar do grau de conhecimento atingido e da gradativa e crescente formação de pessoal específico e especializado para essa função $0^{9-11}$.

Diante dessa situação insuficiente e grave haveria muitas alternativas de respostas técnicas e gerenciais, mas entende-se que criar uma nova cultura sobre as responsabilidades no controle das infecções hospitalares não significa apenas realizar individualmente descobertas originais; significa também e, sobretudo, difundir criticamente verdades já descobertas, divulgá-las e fazer com que se tornem base de ações vitais. Pensando nas possibilidades da melhoria do quadro vivido, entende-se que além da ação de médicos, enfermeiros, farmacêuticos e outros técnicos reafirma-se a importância da presença de novas forças sociais, visando a concretização dos interesses da cidadania. Esse enfrentamento amplo envolve o conjunto da sociedade e suas instituições no direcionamento de novas relações sociais na produção dos cuidados de saúde. Assim, no centro do processo de mudança está a construção do bloco de forças políticas capaz de disputar a hegemonia dos rumos da saúde a partir de uma valorização dos profissionais, dos usuários e dos cidadãos ${ }^{12}$.

Em termos jurídicos, tal situação de fragilidade do controle das infecções hospitalares sugere que a sociedade tem sido hipossuficiente para lidar com a questão, isto é, tem sido incapaz de defender autonomamente seus direitos e passaria a convocar instituições da justiça para atuarem de forma afirmativa para protegê-la. A atuação democrática das instituições jurídicas, apartada de pretensões messiânicas, pode muito contribuir para essas novas relações entre estado e 
sociedade, pois estão constitucionalmente compromissadas em defender e ampliar as conquistas dos direitos sociais. Nesse sentido, uma melhoria do quadro poderia ser buscada no maior diálogo entre a sociedade, as instituições de saúde e o Ministério Público (MP), que se justifica por fundamentos jurídicos e políticos que alicerçam possibilidades de ações conjuntas.

\section{A Constituição cidadã e a saúde}

A saúde, a partir da Constituição Federal de $1988^{13}$, não é mais qualquer questão de natureza coletiva, é afirmada como um direito social. Um amplo movimento social foi constituído aos tempos da luta pela redemocratização do país. A saúde foi bandeira de resistência democrática por muitos anos, em muitas cidades, bairros, regiões do campo, e no movimento sindical. Ela despertava interesse, agrupava, expunha contradições e favorecia de forma difusa e atomizada espaços de debate e mobilização. A partir destes embates contra a ditadura, como pano de fundo, no plano dos saberes viabilizou-se uma prática de questionamento às concepções da saúde e à organização dos serviços que também se expressava internacionalmente, particularmente após a realização da Conferência de Alma-Ata, no ano de 1978. Assim, paulatinamente, uma proposta técnica vai estabelecendo o conteúdo para uma proposta de reforma política setorial ${ }^{14}$.

Na Reforma Sanitária proposta e efetivada na nova Carta refutou-se a conceituação da saúde como uma mercadoria a ser ou não consumida conforme as posses individuais ou como benefício contributivo resultante de um sistema de proteção. Ela não é uma questão de consumidores, ou de indigência ou de benemerência. Ela passou a ser expressão da conquista de um direito de cidadania em respeito à dignidade da pessoa humana.

A partir dessa definição legal-formal a saúde comporta-se conceitualmente como uma antimercadoria ${ }^{15}$ no interior do sistema capitalista, o que certamente resulta na natureza extremamente polêmica e repleta de avanços e retrocessos. Daí a importância de considerar o direito à saúde, incluído na Constituição e nas Leis Ordinárias que regulam a questão, não como uma medida criada juridicamente e a ser desenvolvida por decreto ou por gestões meramente técnicoadministrativas, mas, acima de tudo, como um recurso jurídico e político conflituoso, não obstante sua configuração formal. A saúde como direito social e a ação das forças sociais para sua efetiva realização, ou não, são, portanto, a marca fundamental deste novo período das políticas públicas de saúde ${ }^{16}$.

A saúde é questão assumida formalmente pelo conjunto da sociedade como direito de cidadania e, portanto, universal, igualitário, não contributivo e financiado pelos fundos públicos, configurando-se, assim, a nova conjuntura político-social. É em torno dessa nova condição, da saúde como direito do cidadão e dever do Estado, formalmente reconhecida como de relevância pública e das obrigações do poder público, que se abre a disputa pelos fundos públicos na qual diferentes projetos passam a se articular. Pólos em disputa no interior do poder público, articulados ou não com interesses privados que mantem atividades de saúde balizadas pelo princípio mercadológico, estão concretizados, centralmente, nos embates entre prover o mínimo contra prover o básico. Essa disputa pela maior ou menor abrangência do direito à saúde desdobra-se na prática cotidiana dos serviços nas distintas propostas de como operacionalizar a universalidade e a integralidade das ações do SUS. As políticas públicas voltadas para o provimento do mínimo tem o significado de menor, de menos, identificado com patamares de satisfação de necessidades que beiram a omissão, acompanhado por supressão ou cortes de atendimentos. Já o provimento do básico expressa algo fundamental, principal, primordial, que serve de base de sustentação indispensável ao que a ela se acrescenta. O básico requer investimentos sociais de qualidade que preparem o terreno para o surgimento de outras necessidades, que questionem os limites da própria estrutura social e das relações sociais vigentes. Mínimo e básico não são a mesma coisa; do ponto de vista prático, conceitual e político, são noções assimé$\operatorname{tricas}^{17}$. A concepção de básico é dinâmica, é a capacidade de aprender com a realidade e incorporar de forma permanente novas necessidades. Trabalhar com o básico é trabalhar com um caminho sempre a percorrer, sempre a alargar e não com um ponto de chegada ${ }^{18}$.

\section{Ação política e o alargamento da cidadania}

Esta situação impõe a necessidade de se compreender tais questões como características da esfera da ação política que é, também, onde lidamos com o exercício e as dissimetrias de poder. Como propõe Konder ${ }^{19}$ : É na politica que as pessoas podem criar os meios de combinar seus interesses particulares ou corporativos com o interesse geral. É na política que os valores éticos são desafi- 
ados a serem traduzidos na prática, na ação, definindo a ligação entre a esfera privada e a esfera pública. Assim, a política não é a simples concretização de um pacto de interesses considerados estáveis ou imutáveis, não é o simples somatório de interesses particulares ou corporativos; há nessa passagem do interesse individual para o interesse da generalidade humana um salto qualitativo em que a política se faz necessária.

A idéia de crise da política vivida pela sociedade, no fundo, sugere que a crise chegou ao âmago da vida social, dificultando terrivelmente o acúmulo de energias criativas. A desmoralização da política, a descrença da sociedade em geral nas ações coletivas e na ética do bem comum são marcas dos tempos atuais. "A crise da política é o embaçamento das condições para que se supere o mal-estar coletivo e se encontre um novo rumo." A crise da política é o domínio do mercado, do capital financeiro transnacional sobre o Estado, o enfraquecimento das instituições, da ética e da cultura da solidariedade ${ }^{20}$.

Esta situação, sempre muito instável e cheia de avanços e revezes, apresenta-se nos dilemas e dificuldades da implementação do SUS, na disputa pelo provimento mínimo versus o básico do direito à saúde, na disputa pelos fundos públicos. Isto é, a ética do direito à saúde abrangente e radical é conflituosa com a lógica de funcionamento do sistema social vigente. A participação da população nos destinos da saúde formalmente regulamentada pela Lei federal $n^{\circ} 8142^{21}$ tem assim uma grande responsabilidade e missão, qual seja, a de exercer um papel ativo e ser fator impulsionador das transformações e conquistas da cidadania.

Na vigência previsível dessas disputas, a Constituição Federal de $1988^{13}$ produziu uma outra grande mudança: arremessou as instituições judiciais à esfera da política, especialmente quando consolidou um novo perfil do Ministério Público, paulatinamente construído ao longo dos anos 70 e 80 nos embates pela democratização, retirando-o da alçada do poder executivo, conferindo-lhe maior autonomia administrativa e independência funcional e deslocando-o da tarefa da defesa do Estado para a condição de fiscal dos direitos da sociedade ${ }^{22,23}$.

Para tanto, dotou esse órgão renascido de instrumentos judiciais e extrajudiciais para a defesa dos direitos individuais homogêneos, coletivos e difusos - respectivamente a ação civil pública e o inquérito civil, que por sua vez abre a possibilidade de uma ação política singular na construção de compromissos de ajustamento de conduta, o que tem permitido que o MP atue de forma original e produtiva na defesa desses direitos transindividuais instituídos por lei. Tal defesa jurídica de direitos de dimensão coletiva, positivados em diplomas legais, configura uma nova ação dentro do ordenamento jurídico tradicional, então essencialmente individualista, alargando o acesso de demandas coletivas à Justiça $^{22}$. São ações jurídico-políticas, frutos da intervenção do Poder Legislativo, constituinte e ordinário, e da apropriação desenvolta que a cidadania faz do novo quadro institucional, e que não significam a perda das diferenciações funcionais entre o direito e a política ${ }^{24}$.

Não menos importante foi a conceituação ampliada sobre a saúde, também fixada na Constituição. Tal conceito retoma o entendimento histórico-social e coletivo na determinação da doença (artigo 196) ${ }^{13}$, também aplicável às infecções hospitalares, estabelecendo um outro ponto de vinculação das ações e das finalidades da promoção e proteção da saúde com a concepção jurídica dos direitos transindividuais, foco de atuação do MP.

Essa tutela de interesses coletivos (aqui entendida na sua conceituação jurídica sem valoração paternalista e autoritária), aí incluído o direito à saúde, promovida pelo MP e voltada para a construção da cidadania, constitui uma nova arena judicial para a solução de conflitos no âmbito dos direitos sociais, que não tinham acesso ao sistema de justiça $a^{22}$.

Trata-se, portanto, de um movimento interdependente e complexo gerado na aproximação das ações de instituições políticas e jurídicas em atenção aos direitos sociais fixados, demarcando o novo cenário político em disputa pós-constituinte. Nesse quadro é francamente insuficiente propor-se a acompanhar tal questão social nos moldes de quantificações de casos de infecção, independentes do contexto gerador. Não se menospreza a importância e o direito da população conhecer a situação, tampouco imagina-se que a sociedade seja incapaz de lidar com informações. Não se trata disso, alerta-se nesse caso, em especial, que conhecer dados estatísticos não significa conhecer a problemática, pois um dado bruto é limitado e obtuso, quando apartado do contexto. O acompanhamento ou a divulgação desavisada e acrítica de números de casos podem ter um efeito deletério, pois premiam os mais desorganizados e inoperantes, os subnotificadores que nem sequer estão reconhecendo os casos infeciosos de origem hospitalar. Fixar-se na exigência de divulgação de quantidade de casos po- 
deria ter, também, uma resultante de sensacionalismo, útil para interesses menores, porém frágil e desorganizadora para o controle efetivo dos processos a serem cumpridos.

Assim, sugere-se que nessa área do direito, ainda em construção, deva-se ficar atento para as fontes da construção das normas sobre o controle das infecções hospitalares no campo do direito sanitário. Relembrando as fontes do direito lecionadas por Miguel Reale ${ }^{25}$ em seu entendimento de que o Direito é uma integração normativa de fatos segundo valores, pode-se esperançar que os costumes jurídicos e a jurisprudência impulsionem normas que se recusem a incentivar uma expectativa na esfera jurídica de que, no fundo, seja possível a imediata erradicação das infecções hospitalares. A impaciência ao lidar com a complexidade do problema pode resultar, nesse caso, numa abordagem pouco útil para atuar na realidade e efetivamente superar as insuficiências, precipitando-se na fixação de um prestígio ao formalismo abstrato do direito, apressadamente compromissado como meio imediato para a manifestação das tendências materiais egoístas da vida social ${ }^{26}$.

Definir indicador deve ser um caminho para se aproximar da compreensão do funcionamento do todo. Seja para avaliação, seja para monitoramento, os indicadores não podem ser entendidos como objetivos de uma ação ou da gestão, desvio muito comum que ocorre, exemplarmente, quando níveis hierárquicos com menor poder obrigam-se a colocar indicadores no centro da missão, por sentirem-se vulneráveis a cobranças externas, muitas vezes, sem sentido operacional real ${ }^{18}$.

Rattner $^{27}$, criticando a tendência de transformar indicadores em centro da problemática de desenvolvimento de uma política social ou econômica, afirma que esse caminho pressupõe erradamente que indicadores estatísticos constituiriam um retrato fiel da realidade e que a tarefa mais importante passaria a ser o aperfeiçoamento do sistema de informações, ou seja, melhores indicadores levariam automaticamente a uma política social mais eficaz e justa, orientada e controlada pelos tecnocratas cujo modelo de organização social seria um sistema baseado no consenso.

Nenhum indicador pode ser entendido como absoluto, trata-se apenas de mais um instrumento. Os indicadores não explicam nada: fornecem informações para uma explicação, que aliados e integrados à análise do contexto e dos processos tem sua contribuição ${ }^{18}$.

\section{Conclusão}

Instrumentos constitucionais e das leis ordinárias têm sido postos em ação, com a participação do cidadão, na defesa do direito à saúde e no controle social das obrigações do Estado. As instituições jurídicas contribuem com esse processo permanente e sempre inacabado da democratização. A crescente intervenção da justiça e do Ministério Público em questões envolvendo ocorrências de infecção relacionada a serviços de saúde e as dificuldades evidentes das instituições de saúde em levarem a cabo as tarefas necessárias de controle refletem o patamar de qualificação dos serviços de saúde no Brasil.

A análise dos processos de controle das infecções hospitalares pode fornecer mais do que os casos individuais, que obviamente não podem deixar de ser apontados. A verificação crítica das condições em que se processa o controle em cada instituição pode produzir importantes informações, constituindo-se numa condição marcadora, entendida como uma técnica para avaliação da atenção que se baseia na concepção de que a avaliação da assistência prestada a um conjunto determinado de condições possa revelar a qualidade da atenção à saúde em geral ${ }^{28}$. O acompanhamento das atividades de controle da infecção em serviços de saúde pode, portanto, propiciar uma avaliação global da assistência prestada, transformando-se num poderoso instrumento para um profícuo e amplo trabalho conjunto do Ministério Público com instituições da saúde e da participação cidadã.

\section{Agradecimentos}

Agradeço as sugestões de Fernando Aurélio Calligaris Galvanese e de Rosana Fiorini Puccini. 


\section{Referências}

1. Thorwald J. O século dos cirurgiões. São Paulo: Hemus; 2002.

2. Céline LF. A vida e a obra de Semmelweis. São Paulo: Companhia das Letras; 1998.

3. Kuhn TS. A estrutura das revoluções científicas. $5^{\mathrm{a}}$. ed. São Paulo: Perspectiva; 1998.

4. Fernandes AT. Semmelweis: uma história para reflexão. [acessado $2009 \mathrm{fev}$ 19]. Disponível em: http:// www.ccih.med.br/semmelweis.html

5. Muñoz Sanchez AI, Bertolozzi MR. Operacionalização do conceito de vulnerabilidade à tuberculose em alunos universitários. Cien Saude Colet 2011; 16(2):669-675.

6. Kosik K. Dialética do concreto. São Paulo: Paz e Terra; 1995.

7. Brasil. Lei Federal $n^{\circ} .9431 / 1997$. Dispõe sobre a obrigatoriedade da manutenção de programa de controle de infecções hospitalares pelos hospitais do País. Diário Oficial da União 1997; 7 jan.

8. Brasil. Ministério da Saúde. Portaria no ${ }^{\circ}$. 2616. Expede na forma de anexos diretrizes e normas para a prevenção e controle das infecções hospitalares. Diário Oficial da União 1998; 13 maio.

9. Agência Nacional de Vigilância Sanitária (ANVISA). Informes sobre regulação de medicamentos e sistema de controle de infecção hospitalar. Rev Saude Publica 2004; 38(1):145-148.

10. Turrini RNT. Programa de controle de infecção hospitalar: problemas na implementação em hospitais do município de São Paulo. Acta Paul Enferm 2004; 17(3):316-324.

11. Instituto de Defesa do Consumidor - IDEC. $O$ controle de infecção hospitalar no Brasil e os consumidores. São Paulo; 2006. mimeo.

12. Gruppi L. O conceito de hegemonia em Gramsci. 3a. ed. São Paulo: Graal; 1991.

13. Brasil. Constituição da República Federativa do Brasil. Brasília: Senado Federal; 1988.

14. Puccini PT. Limites e possibilidades da proposta de humanização dos serviços e satisfação dos usuários na disputa pelo direito à saúde [dissertação]. Campinas: Faculdade de Ciências Médicas, Universidade Estadual de Campinas; 2002.

15. Oliveira F. Os direitos do antivalor: a economia política da hegemonia imperfeita. Petrópolis: Vozes; 1998.

16. Puccini PT, Cecílio LCO. A humanização dos serviços e o direito à saúde. Cad Saude Publica 2004; 20(5):1342-1353.
17. Potyara APP. Necessidades humanas: subsídios à crítica dos mínimos sociais. São Paulo: Cortez Editora; 2000.

18. Puccini PT. Análise de instrumentos de apoio ao monitoramento dos serviços de atenção básica [tese]. São Paulo: Faculdade de Saúde Pública, Universidade de São Paulo; 2005.

19. Konder L. Os sofrimentos do "homem burguês". São Paulo: Senac; 2000.

20. Nogueira MA. Em defesa da política. São Paulo: Senac; 2001.

21. Brasil. Lei Federal nº. 8.142/1990. Diário Oficial da União 1990; $31 \mathrm{dez}$.

22. Arantes RB. Direito e política: o Ministério Público e a defesa dos direitos coletivos. Rev. bras. Ci. Soc. 1999; 4(39):83-102.

23. Silva CA. Promotores de justiça e novas formas de atuação em defesa de interesses sociais e coletivos. Rev. bras. Ci. Soc. 2001; 16(45):127-144.

24. Vianna LJW, Burgos MB . Entre princípios e regras: cinco estudos de caso de ação cívil público. Rev. Cienc. Sociais 2005; 48(4):777-843.

25. Reale M. Teoria Tridimensional do Direito. São Paulo: Saraiva; 1994.

26. Lukács G. Socialismo e democratização. Rio de Janeiro: Editora UFRJ; 2008.

27. Rattner H. Indicadores sociais e planificação do desenvolvimento. [acessado 2004 nov 10]. Disponível em: http//www.espacoacademico.com.br/030/30rattner. htm

28. Penna MLF. Condição marcadora e evento sentinela na avaliação de serviço de saúde. In: Santana JP, coordenador. Desenvolvimento gerencial de unidades básicas do sistema único de saúde. Brasília: OPAS; 1997. p. 121-128.

Artigo apresentado em 23/03/2009

Aprovado em 07/05/2009

Versão final apresentada em 01/06/2009 